\title{
Frações unitárias: contribuições da História da Matemática para o ensino dos números racionais
}

\section{Unit fractions: contributions from the History of Mathematics to rational numbers teaching}

\author{
Wagner Marcelo Pommer ${ }^{1}$ \\ Universidade Federal de São Paulo (UNIFESP), Departamento de Ciências Exatas e da Terra, \\ Pós-Graduação em Ensino de Ciências e Matemática (PECMA), Diadema, SP, Brasil \\ (D) http://orcid.org/0000-0002-6138-1279, 9 http://lattes.cnpq.br/4262149292744127
}

\author{
Franco Vinicius Pinto de Moraes ${ }^{2}$ \\ Universidade Federal de São Paulo (UNIFESP), Diadema, SP, Brasil \\ https://orcid.org/0000-0001-6125-7721, 9 http://lattes.cnpq.br/4246001133662262
}

\begin{abstract}
Resumo: A História da Matemática é um campo que pode trazer contribuições ao ensino de Matemática da escolaridade básica. $\mathrm{O}$ objetivo deste trabalho foi realizar um levantamento histórico-epistemológico sobre as frações unitárias em livros da História da Matemática e analisar as possibilidades de contribuição deste tema para os anos finais do Ensino Fundamental. As pesquisas de Lopes (2008) e Pommer (2020) apontam que o ensino dos números racionais ainda é um assunto aberto para debates acadêmicos. Para essa discussão foi levantado o quadro sobre o ensino de frações assim como da relevância e possíveis contribuições do campo da História da Matemática. Na parte metodológica foi desenvolvida uma pesquisa documental em quatro livros de História da Matemática: Karlson (1961), Boyer (1974), Ifrah (1997) e Roque (2012). Os livros revelaram momentos do desenvolvimento das frações unitárias pelos antigos egípcios que permitem uma conexão com as pesquisas envolvendo números racionais em Educação Matemática. Também foi observado que os contextos culturais envoltos no desenvolvimento das frações unitárias pelo antigo povo egípcio poderiam ser inseridos em situações problematizadoras para fomentar o ensino interdisciplinar, o que contribui para o aprendizado das próprias frações.
\end{abstract}

Palavras-chave: frações unitárias; História da Matemática; ensino; antigos egípcios.

Abstract: The History of Mathematics is a field that can bring contributions to Mathematics teaching at basic education. The objective of this work was to carry out a historical-epistemological survey on the unit fractions in History of Mathematics books and to analyze the possibilities of contribution of this theme to the final years of Elementary School. Research by Lopes (2008) and Pommer (2020) show that the teaching of rational numbers is still an open subject for academic debates. For this discussion we raised the framework on fractions teaching, as well as the relevance and possible contributions of the field of the History of Mathematics. In the methodological part, a documentary research was developed in four History of Mathematics books: Karlson (1961), Boyer (1974), Ifrah (1997) and Roque (2012). The books revealed moments of the development of unit fractions by the ancient Egyptians that allow a connection with research involving rational numbers in Mathematics Education. Still, it was observed that the cultural contexts involved in the development of unitary fractions by the ancient Egyptian people could be inserted in problematic situations to foster interdisciplinary teaching, which contributes to the learning of the fractions themselves.

Keywords: unit fractions; History of Mathematics; teaching; ancient egiptians.

Data de submissão: 25 de dezembro de 2020.

Data de aprovação: 7 de maio de 2021.

\footnotetext{
${ }^{1}$ Currículo sucinto: Doutor em Educação pela Universidade de São Paulo. Contribuição de autoria: Escrita, Investigação. Contato: wagner.pommer@unifesp.br.

${ }^{2}$ Currículo sucinto: Licenciado em Ciências (ênfase em Matemática) pela Universidade Federal de São Paulo. Contribuição de autoria: Escrita, Investigação. Contato: franco vini01@hotmail.com.
} 


\section{Introdução}

Nos Parâmetros Curriculares Nacionais (BRASIL, 1997) e na Base Nacional Comum Curricular, descrita em Brasil (2017), o ensino dos números racionais se situa a partir do $4^{\circ}$ ano e são trabalhados de modo explícito até $\circ 7^{\circ}$ ano do atual Ensino Fundamental de nove anos, momento onde as principais representações significativas de frações estariam presentes.

$\mathrm{Na}$ Base Nacional Comum Curricular encontramos menção que o primeiro momento didático de apresentação do tema propõe que os alunos deveriam "[...] reconhecer as frações unitárias mais usuais $(1 / 2,1 / 3,1 / 4,1 / 5,1 / 10$ e 1/100) como unidades de medida menores do que uma unidade, utilizando a reta numérica como recurso" (BRASIL, 2017, p. 288-289).

Apesar da inserção no currículo de diversas séries do Ensino Fundamental, Nunes e Bryant (1997), Pereira e Zúñiga (2015) e Brito Jr. (2020), dentre outros, indicam que os números racionais representam um tema que os alunos apresentam dificuldades.

Estas dificuldades se estendem até alunos do Ensino Médio, mesmo apesar das intensas pesquisas voltadas para a escolaridade básica. Lopes (2008) acrescenta que diversos aspectos cruciais das frações ainda escapam a aprendizagem e muitos alunos saem da escola sem uma compreensão adequada das frações.

Acreditamos que o enfoque histórico-cultural pode adentrar o espaço da sala de aula e contribuir para o ensino de números racionais. Esta consideração encontra ressonância em Wilder (1968), D’Ambrosio (1999) e Brousseau (2009), autores que consideram a relevância de envolver o aspecto sócio-cultural nas aulas de Matemática.

Em particular, os aspectos culturais poderiam estar mais entrelaçados ao desenvolvimento dos números racionais na escolaridade básica, como nos estudos desenvolvidos por Guerreiro, Serrazina e Ponte (2018) e Miola e Lima (2020). Neste mote, consideramos que o tema dos números racionais ganharia incremento se explorado em atividades inseridas nas interações inter e intradisciplinares, descritas nos mais recentes documentos oficiais brasileiros.

A pesquisa de Bertoni (2004) aponta que algumas características das frações unitárias (aquelas de numerador unitário) poderiam favorecer o trabalho didático com os números racionais nos anos iniciais do Ensino Fundamental. Lopes (2008) acrescenta a possibilidade de lidar com os números racionais nos anos finais do Ensino Fundamental por meio de questões vinculadas aos aspectos culturais. Para o autor, as frações unitárias beneficiam o aluno na descoberta de regularidades, no desenvolvimento de distintas estratégias e na exploração de vários modos de representação.

O Estado da Arte desenvolvido em Pommer (2020) destacou que cerca de sessenta por cento das pesquisas envolvendo frações unitárias utilizam como referencial teórico os significados 
das frações (parte-todo, quociente, razão, operador, medida, probabilidade e reta numérica), inicialmente desenvolvidos em Kieran (1976) e Behr et al. (1983).

Porém, Pommer (2020) realça que os aspectos sociais ou históricos das frações unitárias foram considerados em somente cerca de quinze por cento das monografias analisadas. Ainda, o autor relata que estes acabaram sendo tratados por um viés mais ligado ao aspecto informativo, sem maiores desdobramentos no campo da Educação.

Situados neste mote, o objetivo deste trabalho foi realizar um levantamento históricoepistemológico sobre o tema das frações unitárias em livros da História da Matemática e analisar as possibilidades de contribuição deste tema nos anos finais do Ensino Fundamental.

\section{Os referenciais teóricos}

O aprendizado de frações na educação básica ainda revela dificuldades de alunos, conforme apontam Bertoni (2004) e Lopes (2008). Esses autores levantam a importância de se ensinar frações no ensino básico com base na perspectiva sócio-histórico-cultural, como nas representações decimais do sistema monetário, nas receitas culinárias e em escalas de medidas.

A pesquisa de Behr et al. (1983) revela que o conceito de número racional perpassa seis subconstructos: a relação parte-todo, um número decimal, uma razão, uma divisão (quociente), um operador e uma medida de partes contínuas ou discretas. Os autores afirmam que o entendimento dos números racionais requer uma compreensão do papel de cada um destes subconstructos, assim como pelos modos de inter-relacioná-los.

Em acréscimo, a História da Matemática poderia contribuir ao buscar fontes para situar problematizações e contextos situados na cultura de nossos ancestrais mais antigos. Ainda, esta área revela diferenças e também possíveis conexões com o ensino de Matemática atual.

As práticas educativas se fundam na cultura, em estilos de aprendizagem e nas tradições e a história compreende o registro desses fundamentos. Portanto, é praticamente impossível discutir educação sem recorrer a esses registros e a interpretações dos mesmos (D'AMBROSIO, 1999, p. 97).

Assim, apontamos para a História da Matemática para a busca de subsídios sobre as frações unitárias frente ao ensino de números racionais. Com base nos Parâmetros Curriculares Nacionais (BRASIL, 1997), é possível fazer um movimento presente-passado para situar mudanças, evoluções e contribuições dos conhecimentos em tempos diferentes.

Em se considerando que o homem é um ser histórico permeado pelas interações sociais e o contexto cultural, este é dialeticamente moldado pela cultura que ele próprio cria, conforme expressou Vygotsky1 (1996).

1 Segundo Oliveira (1993), Lev Semenovich Vygotsky (1896-1934), bacharel em Direito em 1917 pela
Universidade de Moscou, estudava história da arte, filosofia e psicologia na Universidade Popular de
Shanyavskii. Oliveira (1993) relata que Vygotsky trabalhou e pesquisou no Instituto de Psicologia de 
Deste modo, o estudo dos contextos históricos poderia acrescentar contribuições para o ensino da Matemática na escolaridade básica, pois o trajeto das ideias pelo tempo permite emergir dúvidas, dificuldades e escolhas inerentes a busca do conhecimento por alguns personagens das civilizações antigas.

Considerações de Panasuk e Horton (2013, p. 37, tradução nossa) apontam que "[...] a História da Matemática oferece inúmeras oportunidades para rastrear as raízes e o desenvolvimento da humanidade, o desenvolvimento das civilizações e provavelmente afetará a percepção dos alunos sobre o poder da matemática"2.

Miguel (1997) e Schubring (2005) salientam que uma das funções da área da Historiografia é contribuir para se observar e analisar como ocorreu o desenvolvimento de temas matemáticos. Os autores consideram que a História da Matemática favorece a contextualização por meio de fatos que realmente se sucederam, o que permite motivar e enriquecer a compreensão conceitual dos alunos, antecipar ou diagnosticar concepções e obstáculos para o preparo de material para os alunos da escolaridade básica.

Pessoa Jr. (1996) aponta que o estudo da metodologia da Historiografia pode aguçar o olhar do professor ou pesquisador para que a apresentação de alguns temas possam ocorrer de diferentes modos na escolaridade básica.

Por último, relembramos Ginzburg (2001) que sugere o 'estranhamento' como uma possível estratégia para se promover compreensão sobre certas realidades, pois abre oportunidade para se enxergar outras possibilidades para se conhecer certo objeto. Nesse sentido, a nossa opção foi realizar um levantamento em livros de História da Matemática para buscar, descrever e analisar como as frações unitárias poderiam contribuir para o ensino dos números racionais nos anos finais do Ensino Fundamental.

\section{Os referenciais metodológicos}

Corsetti (2006) coloca que a Educação e a investigação histórica caminham lado a lado. Com o alargamento das pesquisas na confluência entre História e Educação torna-se necessário problematizar as fontes, de modo que a História "[...] se faz a partir de qualquer traço ou vestígio deixado pelas sociedades passadas e presentes e que, em muitos casos, as fontes oficiais são insuficientes para compreender aspectos fundamentais" (CORSETTI, 2006, p. 35-36).

Moscou, tendo como foco de estudo as funções psicológicas superiores, que têm suporte biológico, pois são produtos da atividade cerebral, mas se fundamentam nas relações sociais entre o indivíduo e o mundo exterior, as quais se desenvolvem imersas em um processo histórico.

2 "[...] the History of Mathematics supplies endless opportunities to trace the roots and development of humanity, development of civilizations, and is likely to make an effect on students' perception of the power of mathematics". 
Um tipo de pesquisa importante na Historiografia é a pesquisa documental. Segundo SáSilva, Almeida e Guindani (2009, p. 5), a pesquisa documental "[...] é um procedimento que se utiliza de métodos e técnicas para a apreensão, compreensão e análise de documentos dos mais variados tipos.

Pimentel (2001) coloca que esta metodologia requer a organização do material para processar a leitura segundo algumas técnicas, tais como fichamento e levantamento de dados quantitativo ou qualitativo, de modo a facilitar o controle e manuseio das informações para o estabelecimento das categorias ao final das análises.

Ressaltamos a relevância de utilização de livros da História da Matemática como fonte primária de dados, pois há diversos fatores que podem influenciar a apresentação e as temáticas envoltas no tema das frações unitárias. Nesse sentido, acrescentamos que um olhar aguçado sobre o processo histórico das frações unitárias poderia estimular novas percepções envolvendo o uso didático das frações em sala de aula.

Smith (1923) aponta que os livros de História da Matemática seguem uma tipologia básica: cronologia, assuntos, biografia e diversos. Neste texto, a opção foi escolher o material de pesquisa na ordem cronológica e por assunto para efetivar a pesquisa documental.

A classificação cronológica é a mais comum nos livros de História de Matemática. Segundo Pommer (2018), este material é voltado para descrever as ações feitas por cada povo em uma linha sucessiva de tempo baseando-se em documentos disponíveis sobre aqueles povos. Ainda, os livros de História da Matemática voltados a exposição por assunto possibilitam um olhar mais direto e abrangente sobre certo tema, o que pode apresentar correlação com um possível trabalho didático em sala de aula, já que o currículo de Matemática é moldado por conteúdos.

Inseridos nesta perspectiva, os crivos utilizados para a escolha do material analisado foram: (i) O livro tem como tema a História da Matemática (como um todo ou em parte dela); (ii) Os livros de História da Matemática são fontes primárias; (iii) O livro deveria conter a história do Antigo Egito e abordar as frações egípcias.

Dentre o acervo próprio, escolhemos uma amostra de quatro livros , conforme apresentado no Quadro 1. 
Quadro 1 - Escolhas dos livros de História de Matemática para análise das frações unitárias.

\begin{tabular}{|l|c|c|}
\hline \multicolumn{1}{|c|}{ Livros } & Cronologia & Assunto \\
\hline A Magia dos Números, de Paul Karlson, edição (esgotada) de 1961. & & $\mathrm{X}$ \\
\hline História da Matemática, de Carl Benjamin Boyer, publicado no Brasil em 1974. & $\mathrm{X}$ & \\
\hline $\begin{array}{l}\text { Os Números: A História de uma grande invenção, de Georges Ifrah, edição de } \\
1997 .\end{array}$ & & $\mathrm{X}$ \\
\hline $\begin{array}{l}\text { História da Matemática: Uma visão crítica, desfazendo mitos e lendas, de Tatiana } \\
\text { Roque, edição de 2012. }\end{array}$ & $\mathrm{X}$ & \\
\hline
\end{tabular}
Fonte: Elaboração dos autores (2021).

Dos quatro livros, dois se situam na perspectiva 'cronológica' da História da Matemática e outros dois no viés 'assunto' (Os números). Os livros de ordem cronológica escolhidos assinalam um livro clássico da literatura de destaque internacional (BOYER, 1974) contrapondo com uma publicação de uma pesquisadora brasileira atuante na área da Historiografia (ROQUE, 2012).

$\mathrm{Na}$ categoria assunto foram considerados dois livros, um de autoria de grande abrangência publicitária internacional atual (IFRAH, 1997) e outro de uma edição esgotada de divulgação científica que se utiliza de uma linguagem mais informal (KARLSON, 1961).

A seguir, apresenta-se o levantamento de dados e análise em cada um dos livros de História da Matemática escolhidos.

\section{Resultados e discussão}

\subsection{Frações unitárias no livro de Paul Karlson}

O livro de Paul Karlson, de edição de 1961 (esgotada), é conhecido como um clássico da literatura de divulgação científica. O autor utiliza uma linguagem informal e pormenorizada para discorrer sobre o tema dos números, algo bastante raro em obras de divulgação científica.

Karlson (1961) destaca que a linguagem presente no Papiro de Rhind ${ }^{3}$ foi decifrada pelo egiptólogo alemão August Eisenlohr no ano de 1877, sendo "[...] uma das mais antigas cartilhas de cálculo do mundo" (p. 52), desenvolvida na civilização egípcia ${ }^{4}$. Este Papiro foi creditado ao escriba Ahmes e pretendia expor as "[...] regras para se chegar ao conhecimento de todas as coisas [...] de todos os segredos que as coisas encerram" (p. 53).

${ }^{3} \mathrm{O}$ Papiro Rhind é assim denominado por ter sido copiado pelo escriba Ahmes ou Ahmoses, em cerca de 1650 a.C, a partir de um manuscrito de um período pelo menos 200 anos anterior. Boyer (1974) destaca que o Papiro - um rolo de 0,30m por $5 \mathrm{~m}$ - foi adquirido em 1958 pelo antiquário Henry Rhind perto das margens do rio Nilo. O Papiro de Rhind ou Papiro de Ahmes fica guardado no Museu Britânico, apesar da reinvindicação de posse pelo governo atual do Egito.

${ }^{4}$ Oficialmente, é assumido que a civilização egípcia antiga desenvolveu-se no nordeste africano a partir de 3.200 a.C., quando ocorreu a unificação das porções norte e sul as margens do rio Nilo. 
Quando ensina o cálculo de frações a seus alunos, futuros escribas, Ahmes as reduz ao que ele denomina de frações fundamentais:

[...] isto é, frações cujo numerador são iguais a 1 , tais como $1 / 22,1 / 23,1 / 123$. Fornece uma grande tabela, possivelmente coligida as apalpadelas e por tentativas durante muitos séculos, com cujo auxílio se pode representar uma fração qualquer como soma dessas frações fundamentais. [...] Com auxílio destas frações fundamentais efetua-se, então, a divisão passo a passo e, muitas, vezes, apenas aproximada (KARLSON, 1961, p. 53).

Karlson (1961) relata que os cálculos dos antigos egípcios são 'algo complicado' frente à concepção atual dos números racionais na escolaridade básica. De fato, uma leitura e análise dos problemas apresentados no Papiro de Rhind confirmam a percepção que até mesmo os "[...] discípulos de Ahmes só conseguiam aprender os casos particulares repetindo-os sempre de novo, a duras penas e com inúmeros esforços. Não se deparavam com leis generalizadas; parece mesmo duvidoso que os egípcios chegassem a tê-las possuído" (KARLSON, 1961, p. 53).

\subsection{Frações unitárias no livro de Carl Benjamin Boyer}

No que se refere às frações unitárias ${ }^{5}$, Boyer (1974) descreve que os primeiros registros são oriundos do antigo povo egípcio. No livro, as frações unitárias são abordadas no Capítulo 2, que trata do Antigo Egito. Em particular, no referido capítulo o tema se encontra em um subitem exclusivo: o quarto. Além disso, os dois subtópicos subsequentes ('Operações Aritméticas' e 'Problemas Algébricos') têm como finalidade dar continuidade às frações unitárias, visto que buscam apresentar como esse povo tratava as operações aritméticas usuais, imersas em resoluções de problemas no contexto das necessidades utilitárias do referido povo.

No capítulo dedicado ao Antigo Egito, Boyer (1974) afirma que nas inscrições hieroglíficas 6 este povo fez uso de uma "[...] notação especial para as frações unitárias - isto é, com denominador um. O recíproco de qualquer inteiro [positivo] era indicado simplesmente colocando sobre a notação para o inteiro [positivo] um sinal oval ${ }^{7}$ alongado" (p. 9-10, inserção nossa). Atualmente, as frações unitárias são designadas como aquelas escritas da forma $\frac{1}{n}$ e que conceitualmente denotam o inverso de um número.

A seguir, o autor cita a fração $1 \frac{1}{8}$, que na escrita hieroglífica tinha como notação iiili. Boyer (1974, p. 10) destaca que na "[...] notação hierática o oval alongado é substituído por um ponto,

\footnotetext{
${ }^{5} \mathrm{~A}$ denominação fração unitária não era utilizada pelos antigos egípcios.

${ }^{6}$ Existiam duas formas de escrita: a demótica (mais simplificada) e a hieroglífica (mais complexa e formada por desenhos e símbolos).

${ }^{7}$ Perlim e Lopes (2013) citam que o símbolo não era uma elipse, mas uma boca que ficava na parte de cima, era lido como 'éR' e tinha um sentido de parte.
} 
colocado sobre a cifra para o inteiro [positivo] correspondente. [...] No Papiro Ahmes, por exemplo, a fração $1 / 8$ aparece como $\doteq "$.

Boyer (1974) aponta que os antigos egípcios atribuíam um papel especial a fração $2 / 3$ nos cálculos aritméticos ${ }^{8}$, pois estes não faziam a conversão desta para uma soma de frações unitárias. Assim, para encontrar "[...] o terço de um número primeiramente achavam os dois terços e depois tomavam a metade disso" (BOYER, 1974, p. 10).

O autor considera que os antigos egípcios não concebiam as frações da forma $\mathrm{m} / \mathrm{n}$ como algo elementar, mas como parte de um processo expresso como uma soma de frações unitárias. Para facilitar a redução das frações da forma $m / n$. Boyer (1974) relata que os antigos egípcios consultavam tabelas $^{9}$, que no Papiro Rhind possibilitavam escrever frações do tipo $2 / n$ como a soma de frações unitárias, para todos os números ímpares positivos $(n)$ de 5 a 101.

Neste mote, o supra citado autor elucida alguns exemplos que se encontram no Papiro Rhind. Assim, Boyer (1974) destaca que a fração $2 / 5$ era escrita como $\frac{1}{3}+\frac{1}{15}$ enquanto que a fração $3 / 5$ era escrita como sendo $\frac{3}{5}=\frac{1}{3}+\frac{1}{5}+\frac{1}{15}$.

Boyer (1974, p. 10) ainda cita mais cinco outras decomposições e discute que não há explicação ou referência "[...] por que uma decomposição era preferida a outra, dentre a infinidade possível", com relação à escolha efetivada pelo escriba no referido Papiro ${ }^{10}$.

Como decorrência do fato que a decomposição de frações unitárias como as descritas acima não ser necessariamente única, no início do século $X X$ houve muita especulação em torno da questão: haveria uma fórmula geral que indicasse algum critério para as decomposições propostas na tabela $2 / n$ do Papiro Rhind? No bojo dessa argumentação, Boyer (1974) apresenta e discute dois algoritmos, dentro os vários sugeridos por matemáticos ao longo das pesquisas do século XX por estudiosos frente aos papiros do Antigo Egito ${ }^{11}$.

Boyer (1974) ainda cita que o Papiro Rhind também possui uma pequena tabela para expressar números da forma $n / 10$, onde ' $n$ ' pode ser um valor de 1 a 9 , em que as frações eram expressas das frações unitárias e da fração $2 / 3$. "A fração $9 / 10$, por exemplo, é decomposta como $1 / 30$ mais $1 / 5$ mais $2 / 3$ " (BOYER, 1974, p. 11). A essa tabela da forma $n / 10$ estão associadas problemas que envolvem a divisão de:

\footnotetext{
${ }^{8} \mathrm{~A}$ fração $2 / 3$ era representada por ' $\mathrm{z}$.' em escrita hierática.

${ }^{9}$ Esta tabela não se encontra no livro de Boyer (1974).

10 Não acreditamos que tais discussões matemáticas sejam foco do currículo da escolaridade básica, devido à forte presença de cálculos operatórios e da escrita axiomática.

11 Um dos algoritmos é $\frac{2}{n}=\frac{1}{\frac{n+1}{2}}+\frac{1}{\frac{n(n+1)}{2}}(n$ ḿmpar, $n>5)$ que não fornece a fração $\frac{2}{15}$ da tabela egípcia.
} 
[...] um ou dois ou seis ou sete ou oito ou nove pães entre dez homens, e o escriba usa a tabela para $n / 10$ que acabou de dar. No primeiro problema o escriba tem um trabalho considerável para mostrar que está correto dar a cada homem um décimo de um pão [que deveria ser conceitualmente óbvio para um estudante atual]. Se um homem recebe $1 / 10$ de um pão, dois homens receberão $2 / 10$ ou $1 / 5$ e quatro receberão $2 / 5$, ou seja, $1 / 3+1 / 15$ de um pão. Portanto, oito homens receberão $2 / 3+2 / 15$, ou $2 / 3+1 / 10$ de um pão (BOYER, 1974, p. 11).

Ressaltamos que os problemas acima denotam uma situação real e diária que os egípcios faziam. Isto difere dos problemas fictícios evocados em sala de aula na atualidade, onde não se efetiva a divisão. Boyer (1974) comenta sobre a solução apresentada pelo escriba no problema 'Dividir sete pães para dez homens', onde fez uso de $\frac{7}{10}=\frac{2}{3}+\frac{1}{30}$, ao invés de $\frac{7}{10}=\frac{1}{2}+\frac{1}{5}$, o que marca a preferência dos antigos egípcios pela fração $2 / 3$.

Os antigos egípcios também efetuavam multiplicações com frações unitárias, pelo método das dublações. "O problema 13 no papiro de Ahmes, por exemplo, pede o produto de 1/16 + $1 / 112$ por $1+1 / 2+1 / 4$; o resultado $1 / 8$ é achado corretamente" (BOYER, 1974, p. 11). Mas não há explicação desse processo ${ }^{12}$.

\subsection{Frações unitárias no livro no livro de Ifrah}

O livro "História Universal dos Algarismos - Tomo 1" foi escrito por Georges Ifrah em 1985 e em 1995 recebeu uma $2^{a}$ impressão, tendo sido traduzido para o português em 1997. Aqui foi analisado o Tomo 1, onde se encontra o tema "História de uma Grande Invenção".

No livro, o tema do Antigo Egito tem um capítulo reservado para o mesmo. Trata-se do Capítulo 14 (Os algarismos da civilização dos faraós), apresentado a partir da página 331 . O início do desenvolvimento do tema ocorre no tópico "As frações do número e o deus esquartejado" (p. 348). Nesta seção, Ifrah (1997) começa a mencionar a representação da fração do número e o símbolo da boca, conforme vemos na Figura 1.

Figura 1 - Representação de frações unitárias

\begin{tabular}{|c|c|c|c|c|}
\hline$\stackrel{\square 0}{\square 0}$ & $\underset{000}{00}$ & $\begin{array}{l}\text { 定 } \\
000 \\
000\end{array}$ & 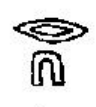 & $\Leftrightarrow$ \\
\hline$\frac{1}{3}$ & $\frac{1}{5}$ & 1 & $\frac{1}{10}$ & $\frac{1}{100}$ \\
\hline
\end{tabular}

Fonte: Ifrah (1997, p. 349)

Ifrah (1997) descreve que quando o número era de ordem maior (do que conhecemos atualmente por denominador), o número era descrito da direita para a esquerda com a sua representação de casas maiores abaixo da boca como evidenciado na Figura 2.

12 Boyer (1974) também menciona que no Papiro há problemas de divisão que envolvem frações unitárias. "O problema 70 requer o quociente da divisão de 100 por $7+1 / 2+1 / 4+1 / 126$ " (p. 11). Acreditamos que tais problemas não se enquadrem no cenário das discussões educacionais atuais. 
Figura 2 - Representação de 1/249

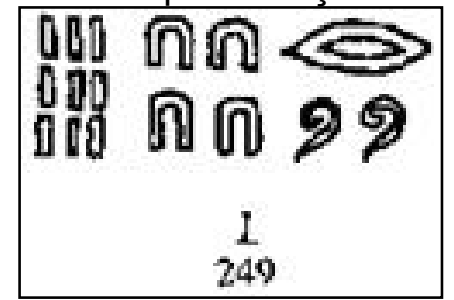

Fonte: Ifrah (1997, p. 349)

Na Figura 2 podemos perceber que o denominador começa exatamente em baixo da boca e se prolonga com os símbolos para simbolizar cada ordem da direita para a esquerda.

A seguir, Ifrah (1997) comenta sobre a relação entre os signos utilizados pelos antigos egípcios e as frações em notação atual, destacado na Figura 3.

Figura 3 - Representações das frações pelos antigos egípcios

Certas fraçōes, como $1 / 2,2 / 3 \mathrm{e} \% / 4$, eram representadas por sinais especiais. Para $1 / 2$ empregava-se simplismente o hiróglifo seguinte (que era lido GeS e que exprimia

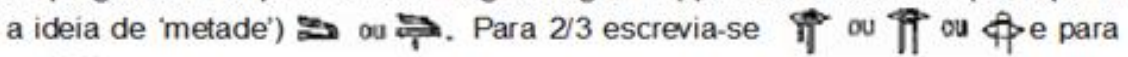
$3 / 4$ 宅 (as três partes).

Fonte: Ifrah (1997, p. 348)

Ifrah (1997) retoma o exemplo $\frac{3}{5}=\frac{1}{3}+\frac{1}{5}+\frac{1}{15}$ apontado anteriormente em Boyer (1974). O autor comenta sobre os problemas do Papiro de Rhind que colocam as medidas de capacidade volumétrica, conhecidas como frações de héqat.

Estas frações remetiam ao 'oudjat', que "[...] era ao mesmo tempo o olho de um ser humano e o de um falcão" (p. 350). Destacamos na Figura 4 o 'oudjat' e as frações do 'héqat'.

Figura 4 - Representações icônicas do oudjat das frações do héqat

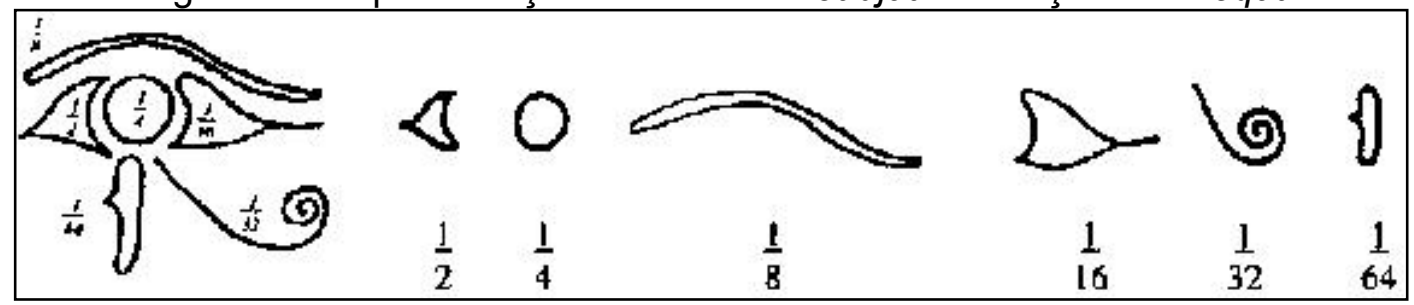

Fonte: Ifrah (1997, p. 350)

Por último, Ifrah (1997) faz uma oportuna observação.

Quando um aluno-escriba observou um dia a seu mestre que o total das frações obtidas a partir do oudjat dava por valor apenas: $1 / 2+1 / 4+1 / 8+1 / 16+1 / 32+1 / 64=63 / 64$, foi-lhe respondido que o $1 / 64$ que faltava para perfazer a unidade seria sempre fornecido por Thot ao calculador que colocava sob sua proteção (p. 354).

\subsection{Frações unitárias no livro de Tatiana Roque}


No livro "História da Matemática: Uma visão crítica, desfazendo mitos e lendas" de Roque (2012), encontramos o desenvolvimento das frações unitárias no tópico 'Matemáticas na Mesopotâmia e no Antigo Egito'.

No referido livro as frações no antigo povo egípcio se inserem nos subitens: 'Números e operações no Antigo Egito' e 'Operações e problemas', expostos no item 'Matemática na Mesopotâmia e no Antigo Egito'.

No primeiro item, o foco do livro de Roque (2012) é estabelecer como os antigos egípcios realizavam as representações numéricas pelos signos daquele aquele povo e as operações realizadas. Na Figura 5 há a indicação da representação de algumas frações unitárias.

Figura 5 - As representações de frações unitárias

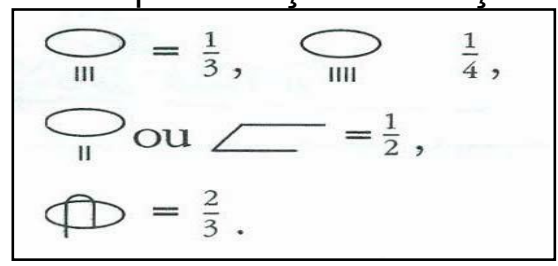

Fonte: Roque (2012, p. 55)

Roque (2012) retoma que as frações unitárias corresponderiam aquelas que atualmente escrevemos pela forma $1 / n$, ou seja, frações que diríamos ter 'numerador unitário'. Os antigos egípcios possuíam a divisão em frações comuns e as frações que possuíam o símbolo oval em cima. Ambas apresentavam um simbolismo diferente do que conhecemos atualmente.

As frações comuns eram representadas por símbolos próprios, escritos em hierático e hieróglifo, como $1 / 2$ (fração representada por $\subset$, em hieróglifo); $2 / 3$ (representada por $\pi$ ); além de $1 / 3$ e $1 / 4$. As outras eram escritas colocando-se um marcador em forma oval (em hieróglifo) em cima do que constituiria, hoje, o denominador. Ou seja, eram obtidas escrevendo os números inteiros com uma oval em cima. Por exemplo, $1 / 7$ seria escrita com a oval sobre sete barras verticais: 吕 (ROQUE, 2012, p. 58).

Roque (2012) descreve que o símbolo oval indica a origem do conceito de ordinal de um número, fato que diferente do atual conceito de numerador na Matemática, que representa um número cardinal. A autora considera que as frações unitárias representariam hoje os inversos de números inteiros. Roque (2012, p. 58) ilustra essa ideia através de uma situação onde "[...] uma pessoa deseja repartir a quantidade de grãos contida em cinco sacos para oito pessoas". Cada uma das cinco pessoas receberá, obrigatoriamente, a quinta parte do objeto.

Roque (2012) explica que na concepção do antigo povo egípcio a primeira repartição seria com quatro sacos de feijão. Assim, na primeira repartição cada uma das oito pessoas receberia a metade $(1 / 2)$ dos grãos. Após isso, em uma segunda repartição, o saco de feijão restante teria 
que ser dividido para as oito pessoas, ficando mais $1 / 8$ para cada um. Dessa forma, cada pessoa receberia $\frac{1}{2}+\frac{1}{8}=\frac{5}{8}$, em notação atual.

Roque (2012) abre um adendo para mostrar como transformar o registro de fração atual, na forma $\mathrm{m} / \mathrm{n}$ como uma soma de frações unitárias. A autora utiliza como exemplo de exposição a fração própria $3 / 7$ (Figura 6).

Figura 6 - Registro de fração na forma $m / n$ como uma soma de frações unitárias

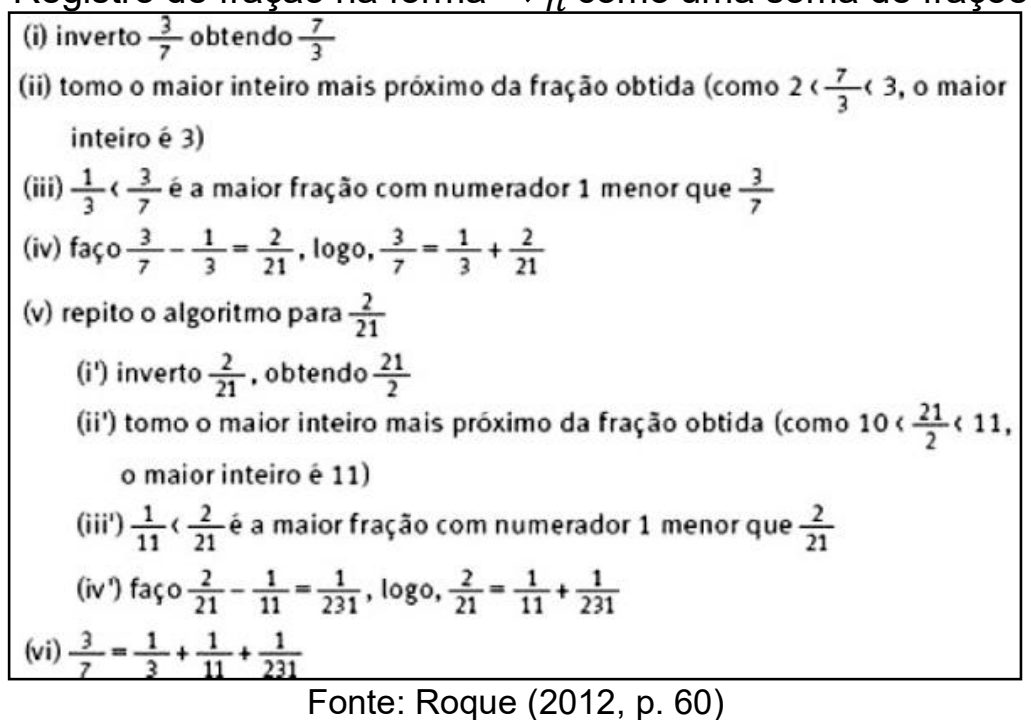

Uma utilização das frações unitárias decorre da operação de divisão. Roque (2012) aponta um exemplo inicial (184:8) para explicar o processo de divisão egípcia. Inicialmente, elabora-se uma tabela de dupla entrada, contendo na $1^{\mathrm{a}}$ linha da coluna da esquerda o número ' 1 ' e na $1^{\text {a }}$ linha da coluna da direita o divisor '8'. A seguir fazem-se dublações conforme Quadro 2a.

\begin{tabular}{|c|c|c|c|}
\hline \multicolumn{2}{|c|}{$a$} & \multicolumn{2}{|c|}{$b$} \\
\hline 1 & 18 & 1 & 18 \\
\hline 2 & $\mid 16$ & 2 & $\mid 16$ \\
\hline 4 & 132 & 4 & 132 \\
\hline 8 & 64 & 8 & 64 \\
\hline 16 & $\mid 128$ & 16 & $\mid 128$ \\
\hline
\end{tabular}

Fonte: Adaptado de Roque (2012, p. 62)

A autora observa que se escrevem linhas um passo antes até que não se exceda o nosso atual 'numerador'. No caso, o dobro de 128 é 256, que não foi escrito. Daí, busca-se na coluna da direita números que somados resultam 184 , que no caso seria: $184=128+32+16+8$. A estas números na coluna da direita correspondem os números $1+2+4+16=23$, destacados em cor cinza no Quadro 2b. Pelo processo egípcio, o resultado de 184:8 é 23.

Roque (2012) deixa a divisão de 185 por 8 a cargo do leitor. Passamos a analisar tal divisão no Quadro 3a. Na expressão $184=128+32+16+8$ adicionamos uma unidade a cada 
membro, para se obter $185=128+32+16+8+1$. Como na coluna da direita não há valor unitário entramos com a fração unitária, conforme Quadro 3.

Quadro 3 - Sequência de dublações da divisão 185 por 8

\begin{tabular}{|c|c|c|c|}
\hline \multicolumn{2}{|c|}{$a$} & \multicolumn{2}{|c|}{$b$} \\
\hline 1 & 18 & $1 / 8$ & 1 \\
\hline 2 & $\backslash 16$ & 1 & 18 \\
\hline 4 & 132 & 2 & $\mid 16$ \\
\hline 8 & 64 & 4 & 132 \\
\hline 10 & 1120 & 8 & 64 \\
\hline 10 & $11 \angle 8$ & 16 & $\mid 128$ \\
\hline
\end{tabular}

Fonte: Elaboração dos autores (2021)

Assim, a divisão de 185 por 8 resulta em $1 / 8+1+2+4+8=23+1 / 8$.

Uma última situação onde Roque (2012) aborda as frações unitárias no enfoque dos antigos egípcios é no método da falsa posição, que em alguns lugares é conhecido como Método A-há13. Roque (2012, p. 63) coloca o problema 25 do Papiro de Rhind: "Uma quantidade e sua metade somadas perfazem 16. Qual é a quantidade".

Como solução, Ahmes inicia com '2' (uma quantidade inicial convenientemente adotada para facilitar o cálculo da metade) e, assim, adiciona '1' (a metade), resultando '3'. No Quadro 4 expusemos a tabela da dublação.

\begin{tabular}{|c|c|}
\hline $1 / 3$ & 1 \\
\hline 1 & 3 \\
\hline 2 & 6 \\
\hline 4 & 12 \\
\hline
\end{tabular}

Fonte: Adaptado de Roque (2012, p. 63)

Daí, efetivam-se as dublações até a linha anterior em que o resultado supere 16. Para obter 16 faz-se $16=1+3+12$ na coluna da direita, a que corresponde $1 / 3+1+4=5+1 / 3$. A boa escolha do problema 25 acarreta em uma solução onde se sobressai o processo e a ideia da correspondência funcional da tabela de dupla entrada. Daí, poderíamos colocar este processo do A-há como um momento pré-funcional da matemática egípcia.

\section{Conclusões}

13 Boyer (1974) também menciona o método da falsa posição. Mas preferimos o exemplo escolhido por Roque (2012), pois os cálculos envolvidos são mais reduzidos, o que favorece o entendimento para alunos do Ensino Fundamental. 
Com base nas análises feitas até aqui, além das discussões acerca de História da Matemática, podemos sintetizar algumas ideias envolvendo as frações unitárias que podem contribuir para o ensino da Matemática na escolaridade básica.

Nos quatro livros analisados encontramos elementos em que as frações unitárias podem beneficiar o aluno na descoberta de regularidades, no desenvolvimento de distintas estratégias e na exploração de vários modos de representação, conforme observação inicial de Lopes (2008).

Ainda, percebemos que os livros por assunto acabaram discutindo o tema das frações unitárias de modo mais informal e contextualizado com o modo social das civilizações antigas, o que permitiu abrir uma janela para conversar com outras áreas, em um mote inter ou transdisciplinar.

Por outro lado, os dois livros de abordagem cronológica se preocuparam de modo mais específico com o tema de um ponto de vista matemático dos antigos egípcios, o que permitiu um olhar comparativo com o ensino atual do tema dos números racionais.

Em consonância, uma característica em comum nos quatro livros quanto ao estudo das frações unitárias pelos antigos egípcios é o aspecto histórico, que pode ser um fator motivador, já que se buscaria entender como os egípcios resolviam seus problemas a cerca de 4000 anos atrás. Dessa forma, os estudantes podem tentar associar os aspectos da sociedade antiga com a realidade atual, buscando entender as relações que poderiam estar conectadas para fazer sentido o conceito de fração, conforme aponta Roque (2012).

Outro fator de destaque das frações unitárias nas coleções é a problematização presente no Papiro de Rhind. Observamos que os dois livros de História da Matemática da abordagem cronológica trazem problemas que se configuram como mais próximos da realidade dos habitantes das civilizações antigas, que envolviam salários e a aquisição de mercadorias. Há uma diferença de costumes que pode ser coloca em relevo e discutidas durante a retomada das problematizações indicadas pelos autores dos livros de História da Matemática analisados.

Ainda, do ponto de vista conceitual, o uso da tabela $2 / n$ permite que os alunos entendam as frações unitárias como um processo. O exemplo dado em Roque (2012) é bem expressivo dessa situação, ao discutir o resultado $\frac{5}{8}=\frac{1}{2}+\frac{1}{8}$, em que o sentido do cálculo aritmético se transfere para a problematização ao se dividir 'cinco pães entre oito homens'. Nada mais natural que o processo de dividir todos os pães na metade $(1 / 2)$ - uma operação fácil de concretizar no mundo real - e depois pegar o que sobrou e subdividir em oito partes, ficando cada homem, ao final, com $1 / 2$ mais $1 / 8$. O processo coincide com os números indicados no registro numérico, o que contribui para significar os cálculos operatórios, algo desejável para a formação de alunos do Ensino Fundamental. 
A concepção de Boyer (1974) e Roque (2012) da fração unitária como inverso de um número é fator que não consta explicitamente nos substratos apontados em Behr et al. (1983) parte-todo, quociente, razão, operador, medida, probabilidade e reta numérica - o que incrementa o rol de significações que uma fração pode ter na escolaridade básica atual.

Outra contribuição dos quatro livros se faz com a transformação de um número em soma de frações unitárias, em que várias propriedades de frações podem ser exploradas nesse procedimento (equivalência de frações, processo de soma/subtração de frações), em um mote de contrapor um processo antigo com o atual, de modo a se estabelecer semelhanças e diferenças. Assim, se instiga no ambiente escolar quais seriam boas formas de escrever frações em cálculos e em problemas, o que permite aflorar diferentes estratégias de resolução.

Vale ressaltar que este trabalho dos antigos egípcios com as tabelas remonta a um momento ou fase pré-funcionalista, pois no seu bojo faz uma conexão com o tema funções. Pommer (2020) não observou esta conexão pré-funcional nas pesquisas mapeadas no Estado da Arte, o que deixa em aberto outra janela para exploração neste viés.

O manuseio de uma fração na forma $\mathrm{m} / \mathrm{n}$ pelos antigos egípcios iniciou pesquisas de diversos historiadores desde o início do século XX. No campo do ensino, as diferentes formas de escrita das frações do tipo $\mathrm{m} / \mathrm{n}$ podem gerar discussões importantes no que tange aos aspectos culturais daquele povo, principalmente relacionados ao fato que as frações unitárias eram utilizadas para fins de partilhas concretas em situações diárias dos antigos egípcios.

Em suma, as frações unitárias podem auxiliar na compreensão da história da criação das frações, além de se relacionar com a formação social egípcia e na constituição histórica, na solução de problemas daquele povo, mas também pode ser instaurada como um elemento desafiador e que visa à compreensão da origem da formação e constituição de toda e qualquer fração, a partir de suas operações.

\section{Referências}

BEHR, M. J; LESH, R.; POST, T.; SILVER, E. Rational number concepts.In: LESH, R.; LANDAU, M. (ed.). Acquisition of mathematics concepts and processes. New York: Academic Press, p. 91-126, 1983.

BERTONI, N. E. Um novo paradigma no ensino e aprendizagem das frações. In: ENCONTRO NACIONAL DE EDUCAÇÃO MATEMÁTICA, 8., 2004, Recife. Anais [...]. Recife: Universidade Federal de Pernanbuco, 2004.

BOYER, C. B. História da Matemática. São Paulo: Edgard Blücher, 1974.

BRASIL. Base Nacional Comum Curricular. Brasília, DF: Ministério da Educação, 2017.

BRASIL. Parâmetros Curriculares Nacionais: Ensino Médio. Brasília: MEC/SEF, 1997. 
BRITO JR., J. J. R. T. TDIC gamificada como complemento da construção do conhecimento de fração sob a perspectiva dos subconstrutos. In: EDUCAÇÃO E TECNOLOGIA DIGITAIS EM CENÁRIO DE TRANSIÇÃO: MÚLTIPLOS OLHARES PARA APRENDIZAGEM, 2020, Campo Grande. Anais [...]. v. 2, n. 1, 2020. Disponível em: https://periodicos.ufms.br/index.php/IntegraEaD/article/view/11803. Acesso em: 12. jan. 2021.

BROUSSEAU, G. A cultura matemática é um instrumento para a cidadania. Por Thais Gurgel. Revista Nova Escola, 1 dez. 2009. Disponível em: https://novaescola.org.br/conteudo/545/guybrousseau-a-cultura-matematica-e-um-instrumento-para-a-cidadania\#. Acesso em: 11 fev. 2021.

CORSETTI, B. A análise documental no contexto da metodologia qualitativa: uma abordagem a partir da experiência de pesquisa do Programa de Pós-Graduação em Educação da Unisinos. UNIrevista, v. 1, n. 1, p. 32-46, jan. 2006. Disponível em: http://gephisnop.weebly.com/uploads/2/3/9/6/23969914/a anlise documental no contexto da pe squis qualitativa.pdf. Acesso em: 9 ago. 2021.

D'AMBROSIO, U. A História da Matemática: questões historiográficas e políticas e reflexos na educação matemática. In: BICUDO, M. A. V. (org.) Pesquisa em Educação Matemática: Concepções \& Perspectivas. São Paulo: UNESP, 1999, p. 97-115.

GINZBURG, C. Estranhamento: Pré-história de um procedimento literário. In: GINZBURG, C. Olhos de Madeira: Nove Reflexões sobre a distância. São Paulo: Cia das Letras, 2001.

GUERREIRO, H. G.; SERRAZINA, L.; PONTE, J. P. A percentagem na aprendizagem com compreensão dos números racionais. Zetetiké, Campinas, v. 26, n. 2, p. 354-374, maio/ago., 2018.

IFRAH, G. Os Números: A História de uma grande invenção. 2. ed. Rio de Janeiro: Nova Fronteira, 1997.

KARLSON, P. A Magia dos Números. Rio de Janeiro: Editora Globo, 1961.

KIERAN, T. E. Number and measurement: mathematical, cognitive and instructional fundaments of frational number. OHERIC/SMEA, Columbus, p. 101-144, 1976.

LOPES, A. J. O que nossos alunos podem estar deixando de aprender sobre frações, quando lhes tentamos ensinar frações. Bolema, Rio Claro, v. 21, n. 31, 2008. Disponível em: https://www.periodicos.rc.biblioteca.unesp.br/index.php/bolema/article/view/2102. Acesso em: 9 ago. 2021.

MIGUEL, A. As potencialidades pedagógicas da História da Matemática em questão: argumentos reforçadores e questionadores. Zetetiké, Campinas, v. 5, n. 2, p. 73-106, jul./dez. 1997. DOI: https://doi.org/10.20396/zet.v5i8.8646848, https://doi.org/10.20396/zet.v5i8.8646849.

MIOLA, A. F. S.; LIMA, T. E. A. Conhecimentos necessários para o ensino de números racionais no Ensino Fundamental. Educação Matemática Debate, Montes Claros, MG, v. 4, p. 1-16, 2020. DOI: https://doi.org/10.46551/emd.e202044.

NUNES, T.; BRYANT, P. Crianças fazendo matemática. Porto Alegre: Artmed, 1997.

OLIVEIRA, M. K. Vygotsky: Aprendizado e Desenvolvimento - Um Processo Sócio-Histórico. São Paulo: Scipione, 1993. 
PANASUK, R. M.; HORTON, L. B. Integrating History of Mathematics into the Classroom: Was Aristotle Wrong? Journal of Curriculum and Teaching, v. 2, n. 2, p. 37-46, 2013. DOI: https://doi.org/10.5430/jct.v2n2p37.

PEREIRA, T. da S.; ZÚÑIGA, N. O. C. Uma investigação sobre as dificuldades dos alunos das séries iniciais do Ensino Médio envolvendo frações. In: ENCONTRO MINEIRO DE EDUCAÇÃO MATEMÁTICA, 7., 2015, São João del Rei. Anais [...]. São João del Rei: UFSJ, 2015. Disponível em: https://docplayer.com.br/amp/18112722-Uma-investigacao-sobre-as-dificuldades-dos-alunosdas-series-iniciais-do-ensino-medio-envolvendo-fracoes.html. Acesso em: 9 ago. 2021.

PERLIM, P.; LOPES, A. R. L. V. A necessidade histórica da criação de frações e a organização do ensino do professor nos anos iniciais. In: CONGRESSO INTERNACIONAL DE ENSINO E EDUCAÇÃO MATEMÁTICA, 6., 2013, Canoas. Anais [...]. Canoas: Ulbra, 2013. Disponível em http://www.conferencias.ulbra.br/index.php/ciem/vi/paper/viewFile/932/907. Acesso em: 9 ago. 2021.

PESSOA JR., O. Quando a Abordagem Histórica deve ser usada no Ensino de Ciências? Ciência \& Ensino, n. 1, p. 4-6, out. 1996.

PIMENTEL, A. O método da análise documental: seu uso numa pesquisa historiográfica.

Cadernos de Pesquisa, n. 114, v. 7, p. 179-195, nov. 2001. Disponível em:

https://www.scielo.br/j/cp/a/FGx3yzvz7XrHRvqQBWLzDNv/?format=pdf\&lang=pt. Acesso em: 9 ago. 2021.

POMMER, W. M. As raízes enésimas irracionais: uma perspectiva a partir das fontes nos livros de História da Matemática. VIDYA, Santa Maria. v. 38, n. 1, p. 185-198, jan./jun. 2018. Disponível em: https://periodicos.ufn.edu.br/index.php/VIDYA/article/view/1991. Acesso em: 9 ago. 2021.

POMMER, W. M. Frações unitárias: um levantamento de dissertações e teses no brasil publicadas entre 2001 e 2018. Ensino da Matemática em Debate, v. 7, n. 1, p. 26-50, 2020. Disponível em: https://revistas.pucsp.br/index.php/emd/article/view/45475. Acesso em: 9 ago. 2021.

ROQUE, T. História da Matemática: uma visão crítica, desfazendo mitos e lendas. Rio de Janeiro: Zahar, 2012.

SÁ-SILVA, J. R.; ALMEIDA, C. D.; GUINDANI, J. F. Pesquisa documental: pistas teóricas e metodológicas. Revista Brasileira de História \& Ciências Sociais, ano 1, n. 1, p. 1-14, jul. 2009. Disponível em: https://periodicos.furg.br/rbhcs/article/view/10351. Acesso em: 9 ago. 2021.

SCHUBRING, G. Pesquisar sobre a história do ensino da matemática: metodologia, abordagens e perspectivas. In: MOREIRA, D.; MATOS, J. M. (org.). História do Ensino da Matemática em Portugal. Sociedade Portuguesa de Ciências da Educação, mar. 2005. Disponível em: http://spiem.pt/DOCS/ATAS ENCONTROS/atas EIEM 2004.pdf. Acesso em: 9 ago. 2021.

SMITH, D. E. History of Mathematics. Boston: Ginn and Co., 1923, v. 1.

VYGOTSKY, L. S. A formação social da mente: o desenvolvimento dos processos psicológicos superiores. 5. ed. São Paulo: Martins Fontes, 1996.

WILDER, R. L. Evolution of mathematical concepts: An elementary study. New York: John Wiley \& Sons, 1968. 